\title{
Abdominal Radiograph in Systemic Sclerosis
}

UEI PUA, MBBS, MMed, FRCR, Department of Diagnostic Radiology, Tan Tock Seng Hospital, 11 Jalan Tan Tock Seng, Singapore 308433. Address reprint requests to Dr. Pua; E-mail: druei@yahoo.com. J Rheumatol 2009;36:654; doi:10.3899/jrheum.080985

Systemic sclerosis can give rise to many findings in the abdominal radiograph. Detection of lung base changes together with "sheet-like" soft tissue calcification and large bowel ileus are important clues to a unifying diagnosis of systemic sclerosis.

A 51-year-old woman presented with a history of several months' duration of abdominal distension and constipation. The abdominal radiograph (Figure 1) showed evidence of large-bowel dilatation of the transverse colon, with normal mucosal features and fecal loading in the sigmoid and rectum. Additionally, there was evidence of florid soft-tissue calcification involving bilateral iliacus muscles. The lung bases showed reticular shadowing with pleural thickening, consistent with pulmonary fibrosis. The constellation of signs - muscle calcifications ${ }^{1}$, pulmonary fibrosis ${ }^{2}$, and nontoxic megacolon ${ }^{3}-$ indicates systemic sclerosis, with bowel atony accounting for the patient's presentation. The hand radiograph (Figure 2) shows the classic appearance of

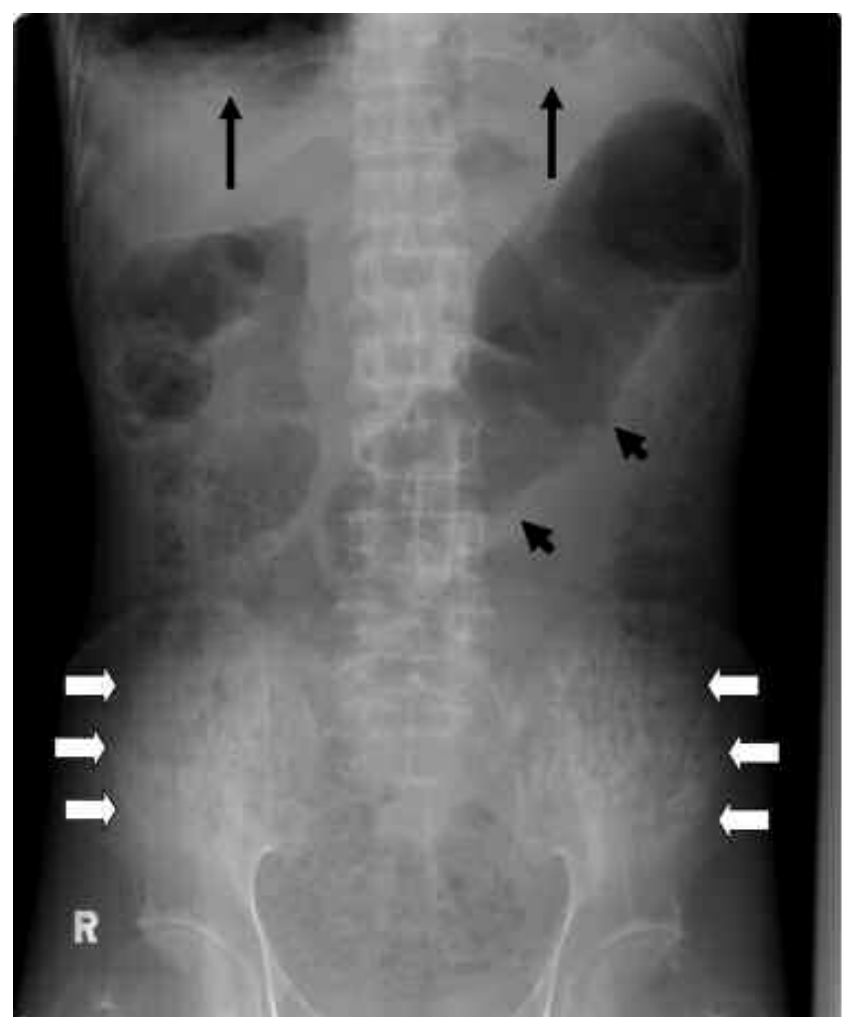

Figure 1. The abdominal radiograph shows evidence of dilatation of the transverse colon, with normal mucosal features (arrowheads) and fecal loading. systemic sclerosis — distal phalanx resorption with soft-tissue calcinosis.

\section{REFERENCES}

1. Ringel RA, Brick JE, Brick JF, Gutmann L, Riggs JE. Muscle involvement in the scleroderma syndromes. Arch Intern Med 1990;150:2550-2.

2. Kaloudi O, Miniati I, Alari S, Matucci-Cerinic M. Interstitial lung disease in systemic sclerosis. Intern Emerg Med 2007;2:250-5.

3. Brandwein M, Schwartz IS. Megacolon and volvulus complicating progressive systemic sclerosis. Mt Sinai J Med 1988;55:343-5.

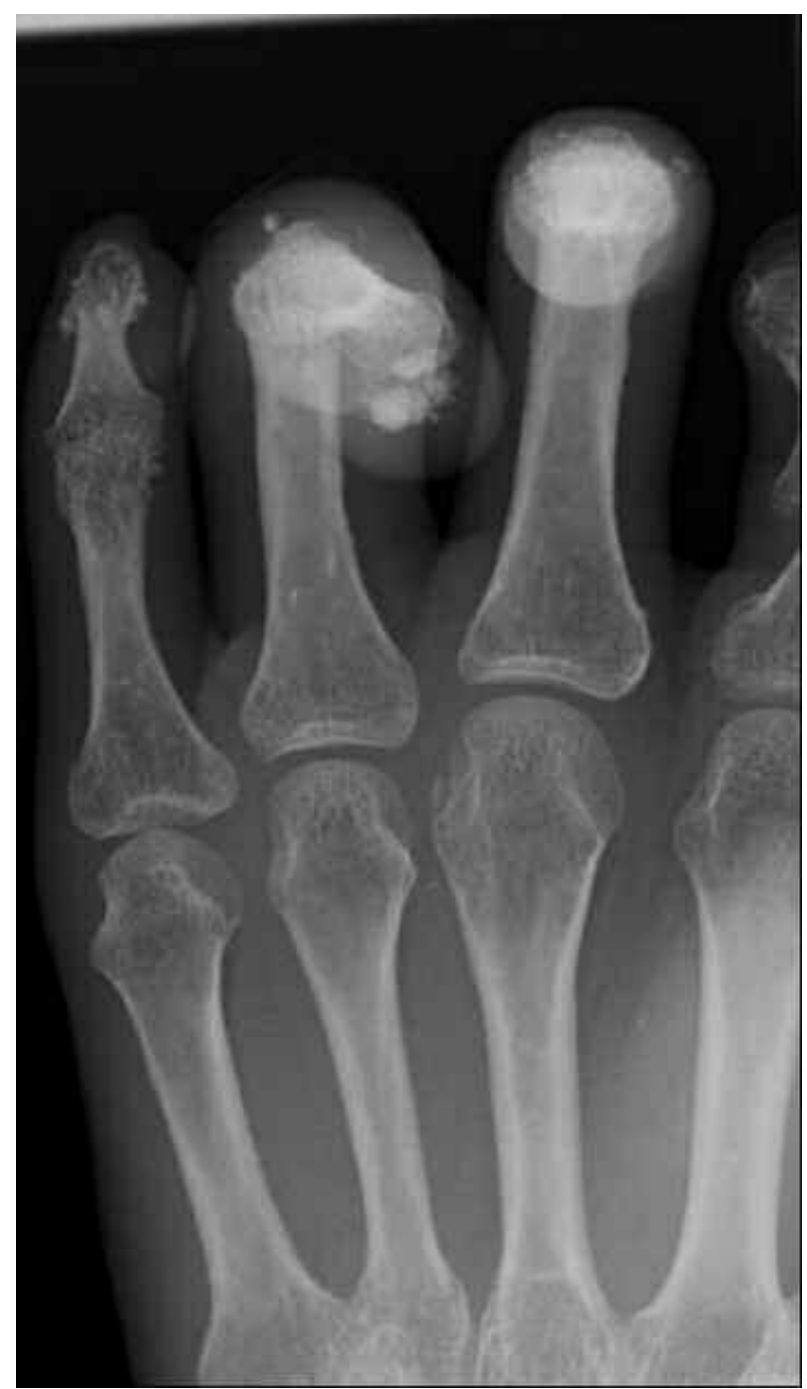

Figure 2. Hand radiograph shows the classic appearance of systemic sclerosis - distal phalanx resorption with soft-tissue calcinosis. 